\title{
Compreendendo o discurso organizacional: características, materialidades e materializações
}

Understanding organizational discourse: characteristics, materialities, and materializations

Comprensión del discurso organizacional: características, materialidades y materializaciones

- Doutor em Ciências da Comunicação pela Escola de Comunicações e Artes da Universidade de São Paulo (ECA-USP).

- Mestre em Comunicação e Informação pela Universidade Federal do Rio Grande do Sul (UFRGS).

- Chefe do Núcleo de Comunicação Interna da Secretaria do Tesouro Nacional (STN).

- E-mail: vieira.magno@gmail.com 


\section{Resumo}

Este trabalho busca refletir sobre a natureza do discurso organizacional. Reconhecendo que o discurso é constituidor e organizador da realidade, apresenta-se uma compreensão de discurso organizacional e a forma como ele é traduzido em/por meio de diversas materialidades e materializações. Para ilustrar como esse discurso se manifesta, são analisadas produções discursivas e comunicacionais das organizações Johnson \& Johnson, Secretaria do Tesouro Nacional, Microsoft e Rede Extra, empregando-se, em termos metodológicos, a análise do discurso de orientação francesa.

PALAVRAS-CHAVE: DISCURSO • DISCURSO ORGANIZACIONAL・COMUNICAÇÃO ORGANIZACIONAL.

\section{Abstract}

This paper seeks to reflect on the nature of organizational discourse. Based on the idea that discourse creates and organizes reality, it presents an understanding of organizational discourse and how it is translated into/through various materialities and materializations. To illustrate the facets assumed by this type of discourse, the study analyzes discursive and communicational productions of Johnson \& Johnson, National Treasury Secretariat, Microsoft, and Rede Extra organizations in the light of the French discourse analysis.

\section{KEYWORDS: DISCOURSE・ORGANIZACIONAL DISCOURSE・ORGANIZATIONAL COMMUNICATION}

\section{Resumen}

Este trabajo pretende reflexionar sobre la naturaliza del discurso organizacional. A partir de la idea de que el discurso es constituyente y organizador de la realidad, se presenta una comprensión de discurso organizacional y cómo este se traduce en/a través de diversas materialidades y materializaciones. Para ilustrar las facetas que asume este tipo de discurso, se analizan las producciones discursivas y comunicacionales de las organizaciones Johnson \& Johnson, Secretaria do Tesouro Nacional, Microsoft y Rede Extra, empleando, metodológicamente, el análisis del discurso de matriz francesa. 


\section{UMA BREVE INTRODUÇÃO}

A s organizações são atores de enorme relevância no mundo atual. Para manterem/exercerem tal relevância, elaboram e colocam em prática estratégias discursivas e comunicacionais. Nesse sentido, a comunicação organizacional acaba por tornar-se uma importante esfera de produção, organização e circulação de materialidades (oferecimento de significações), consolidando-se, assim, como instância de produção discursiva, essencial para o existir das organizações (Silva, 2012).

Consequentemente, são ativados e propostos, por meio de seus processos e produtos, determinados sentidos', com 0 principal objetivo de obter a adesão do(s) público(s) ao que está sendo apresentado/dito. Em uma época de enormes mutações ambientais e tecnológicas, em que a imagem e o dizer adquirem fundamental relevância, a ideia de discurso ganha importância para a comunicação, já que possui potência suficiente para contribuir para a discussão dos processos comunicativos das organizações. Fala-se cada vez mais, portanto, do discurso organizacional.

Assim, refletir sobre o discurso organizacional é a principal tarefa deste trabalho². Apresenta-se uma compreensão sobre 0 tema a partir de conceitos já estabelecidos na seara discursiva. Além disso, procura-se evidenciar, com base em exemplos extraídos da pesquisa empreendida, como esse discurso é traduzido em/por meio de variadas materialidades e materializações que ilustram múltiplas possibilidades para sua caracterização. De forma a cumprir com tal objetivo, traz-se, após esta breve introdução, uma discussão teórica a respeito de discurso e discurso organizacional. Em seguida, são recuperados exemplos, em exercício analítico do ponto de vista comunicacional, de seis produções discursivas (peças) de quatro diferentes organizações - Johnson \& Johnson, Secretaria do Tesouro Nacional (STN), Microsoft e Rede Extra. Nesse momento empírico, são empregados tópicos da análise do discurso (AD) de orientação francesa.

\section{DISCURSO E DISCURSO ORGANIZACIONAL}

Para trazer considerações a respeito do discurso organizacional, julga-se relevante discutir, antes, a ideia de discurso. Esse é um termo que comporta múltiplas definições e abriga as mais variadas vertentes teóricas. Até mesmo no senso comum, é possível localizar uma ideia de discurso traduzida nos quase "bordões" ou ditos, como "Fulano(a) só tem discurso..." ou "Na hora de falar é fácil, vamos ver se o discurso vira realidade..." ou, ainda, "Estamos cansados de discurso! Queremos ver essas promessas virarem prática!". Essas materializações (bastante aceitas, diga-se de passagem) do conceito de discurso parecem tratá-lo, essencialmente, em sentido mais lato, como um ato em que alguém diz algo "ao" ou "sobre" outro.

Talvez como consequência disso, essas acepções contribuem, muitas vezes, para que discurso seja confundido com retórica ou fala, ou que também possa ser visto simplesmente como estratégia de manipulação ou enganação. Parecem estar implicadas nessas visões perspectivas em que o discurso é: 1) tratado como manifestação automática da língua; 2) colocado em uma espécie de lugar de "não-ação"; 3) visto como algo separado da realidade; 4) considerado algo pertencente ao fantasioso, ao não-concreto; e 5) equivalente à mentira. Como são ideias relativamente comuns, Orlandi (2009) fornece alguns elementos para que se desfaçam essas confusões e dá, adicionalmente, pistas para uma compreensão mais complexa para o termo. Segundo a autora:

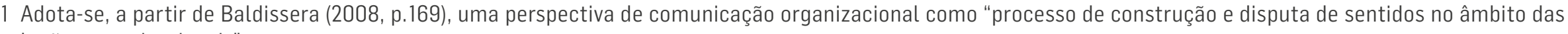
relações organizacionais".

2 Este artigo é recortado a partir da pesquisa que compôs tese de doutoramento já defendida. 
O discurso não corresponde à noção de fala, pois não se trata de opô-lo à língua como sendo esta um sistema, onde tudo se mantém com sua natureza social e suas constantes, sendo o discurso, como a fala, apenas uma [sic] sua ocorrência casual, individual, realização do sistema, fato histórico, a-sistemático, com suas variáveis etc. 0 discurso tem sua regularidade, tem seu funcionamento que é possível apreender se não opomos o social e o histórico, o sistema e a realização, o subjetivo ao objetivo, 0 processo ao produto. (Orlandi, 2009, p.22)

Realizada essa distinção e apesar das confusões e de seu uso indiscriminado para definir uma série de situações cotidianas de (possível) interação, é inegável que o discurso enquanto categoria, objeto de estudo ou aspecto da vida prática adquire grande importância na contemporaneidade. Para Howarth (2000), "o conceito de discurso possui um papel cada vez mais significativo na ciência social contemporânea" (p.1, tradução minha) ${ }^{3}$, servindo como aporte para uma série de campos do conhecimento, seja por sua potência em explicar um determinado estado de coisas, seja por sua capacidade de fornecer instrumental analítico para investigações.

Com isso, é possível capturar uma ideia de discurso que rejeita os esquemas primários/elementares em termos de comunicação - outra área de interseção entre a linguagem e o próprio discurso. Para isso, parte-se da adoção de uma perspectiva sobre o processo discursivo que, não obstante o fato de levar em consideração, seguramente, os processos de linguagem e seus aspectos constituintes, também volta o olhar para aquilo que inicialmente estaria às margens do discurso, mas que, no entanto, não está. Tal perspectiva encontra-se intrinsecamente ligada à questão da construção da realidade à nossa volta.

Dessa forma, toma-se como um dos pontos de partida para esta discussão a existência de íntima relação entre discurso e práxis ${ }^{4}$ e discurso e construção da realidade. São essas algumas das bases da teoria do discurso (TD) de Essex (Inglaterra), formulada a partir dos anos 1980 pelo filósofo argentino Ernesto Laclau. Apesar de originariamente criada em um contexto de pensamento e reflexão sobre a política, seus pressupostos têm fornecido aportes teóricos e analíticos em áreas outras, como a educação e a administração.

A TD engloba pressupostos de arquiteturas teóricas que têm origem, principalmente, "no desconstrutivismo de Derrida acerca da noção de estrutura; no papel das "posições de sujeito" ressaltado por Foucault; na linguística com inspiração saussuriana; e na própria noção de sujeito vinda da psicanálise de Lacan" (Silva, 2015, p.178). Nos dizeres de Laclau e Mouffe (2015a, p.37), "a categoria discurso tem uma genealogia no pensamento contemporâneo que remonta às três principais correntes intelectuais do século XX: a filosofia analítica, a fenomenologia e o estruturalismo".

Balsa (2017) assinala que o conceito de discurso em Laclau é diferente do conceito da linguística. Há, sim, uma preocupação com a produção de significados, mas, anteriormente, a TD analisa as regras e convenções dessa produção dentro de um contexto sócio-histórico (Cunha, 2013). Com isso, a TD apresenta uma concepção de discurso que não é unicamente linguística. Laclau (2008, p.189) pontua:

0 discursivo é, a partir de nossa perspectiva, o campo de uma ontologia geral, quer dizer, de uma reflexão acerca do ser enquanto ser. Isto supõe que as categorias linguísticas deixam de estar ancoradas numa ontologia regional que as reduziria à fala e à escrita, e passam a constituir o campo de uma lógica relacional - fundada na substituição e na combinação, as duas formas primárias da articulação - que constituem o horizonte último do ser enquanto tal.

3 No original: "The concept of discourse plays an increasingly significant role in contemporary social science".

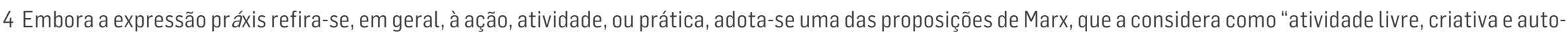

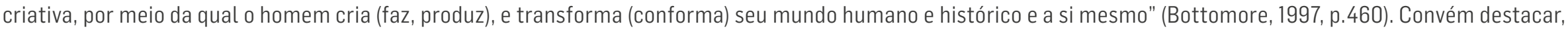
contudo, que a prática é uma das dimensões da práxis, conforme aponta Sánchez Vásquez (1977), da mesma maneira que a teoria também o é. 
A ideia básica de discurso advogada pela TD em Laclau e Mouffe (2015a, 2015b) postula, assim como também postulavam Bakhtin (2011) e Volóchinov (2017), que o discurso é a arena na qual a realidade se constitui. Esse discurso é composto por elementos linguísticos e extralinguísticos, não apenas justapostos, mas também colocados em relação. A TD laclauiana toma por base a ideia de que a linguagem constitui a realidade e, dessa forma, a realidade só existe no interior do próprio discurso que a torna possível (Ferreira, 2011). Outro ponto relevante é que a concepção laclauiana de discurso se constrói em meio a outro tema de interesse de Laclau e Mouffe: o processo de construção da hegemonia, tomado, conceitualmente, a partir da leitura que os autores fazem do filósofo italiano Antonio Gramsci.

Com isso, o espaço social é também, para Laclau e Mouffe (2015b), um espaço discursivo. É nesse sentido que ocorrem as relações de contiguidade entre o linguístico e o extralinguístico. Afirmam os autores:

\begin{abstract}
Suponhamos que estejamos construindo uma parede com mais uma camada de tijolos. Em determinado momento, pedimos para um colega de trabalho que nos passe um tijolo e depois o acrescentamos à parede. 0 primeiro ato - pedir o tijolo - é linguístico; 0 segundo - acrescentar o tijolo à parede - é extralinguístico. Podemos exaurir a realidade dos dois atos traçando uma distinção entre eles em termos da oposição linguístico/extralinguístico? É evidente que não, porque, a despeito de sua diferenciação nesses termos, as duas ações compartilham algo que lhes permite ser comparadas, isto é, o fato de que ambas fazem parte de uma operação total que éa construção da parede. Então, como poderíamos caracterizar essa totalidade da qual pedir um tijolo e posicioná-lo são, ambos, momentos parciais? Obviamente que, se essa totalidade incluir tanto elementos linguísticos como não linguísticos, ela não poderá ser linguística nem extralinguística; ela tem que ser prévia à distinção. Essa totalidade que inclui em si o linguístico e o não linguístico é o que chamamos de discurso....] o que tem que ficar claro desde o começo é que, por discurso, não queremos nos referir a uma combinação de fala e escrita, mas que fala e escrita não passam de componentes internos de totalidades discursivas. (Laclau; Mouffe, 2015b, p.38-9)
\end{abstract}

Dessa maneira, todos os objetos, para a TD, são passíveis de possuírem significação, desde que inscritos em uma totalidade discursiva. Um exemplo disso é fornecido por Ferreira (2011): regularmente, são descobertas novas espécies de animais e vegetais na floresta amazônica; contudo, mesmo antes de suas descobertas, tais espécies já existiam materialmente, porém não possuíam existência no mundo. Somente a partir do momento em que lhes são atribuídos nomes, características e propriedades é que essas espécies passam a entrar em relação com outros elementos - geralmente, por meio de processos de linguagem. Passam, assim, a ser objetos que possuem existência dentro do espaço discursivo.

No entanto, cabe enfatizar que Laclau e Mouffe não desconsideram o dado, aquilo que já está colocado em termos materiais. No exemplo dos tijolos, eles existem e estão inseridos no contexto de uma ação significativa - alguém está efetivamente construindo uma parede com eles. Assim, "não se trata de 'negar' a existência das coisas, mas conferir, por meio do discurso, a inscrição e a demarcação desses objetos na arena discursiva" (Silva, 2018, p.83). Nessa perspectiva, as materialidades (no sentido de "coisas" ou acontecimentos) se tornam objetos discursivizáveis/discursivizados, uma vez que serão resgatados/ recuperados no interior do discurso em algum momento e passarão a compor o campo de uma dada discursividade.

Assim, passam, em última instância, a entrar em relação com um domínio de semânticas e temáticas componentes desse mesmo discurso. É dessa maneira que, para Laclau e Mouffe (2015a, p.180), "todo objeto é constituído como objeto de discurso, uma vez que nenhum objeto é dado fora de condições discursivas de emergência". Levando essa afirmação ao extremo, ao se pensar no exemplo específico enumerado por Ferreira (2011), os objetos dessa inscrição/demarcação são as espécies animais e vegetais; já na ilustração de Laclau e Mouffe (2015b), os objetos são, a seu turno, os tijolos e/ou a parede feita a partir deles.

Embora brevemente expostos, os principais pressupostos da TD da Escola de Essex oferecem um arcabouço potente para se pensar no discurso como elemento constituidor da realidade. Mas, ao mesmo tempo, não há como desconsiderar o primado da linguagem na construção do discurso, por ser ela o elemento que irá propiciar a articulação entre os objetos e os sujeitos 
em torno do discurso. Essa é uma das razões pelas quais não se enxerga uma incompatibilidade entre a concepção discursiva de Laclau e Mouffe e os pressupostos da chamada linha francesa de estudos do discurso/análise do discurso.

A partir dessa concepção, e considerando o âmbito do trabalho e da pesquisa, considera-se discurso, em uma acepção mais geral, como "conjunto organizado de relações e efeitos de sentidos resultante da ação de sujeitos, numa articulação entre os objetos, a(s) linguagem(ns) e o mundo" (Silva, 2018, p.89). Derivada dessa acepção, compreende-se por discurso organizacional "o conjunto de artefatos e práticas, traduzidos em linguagens verbais e não-verbais, mediante a articulação de sujeitos e dispositivos em um dado estado de organização" (Silva, 2018, p.178). Por meio dessa compreensão, providencia-se uma concepção de discurso organizacional que considera, dentre outros aspectos:

o amplo espectro que engloba as práxis organizacionais: em uma medida, objetos (artefatos e/ou acontecimentos), enquanto elementos discursivizados/discursivizáveis, apresentam-se como potencialidades de tradução nas/pelas diversas gramáticas e aparatos linguageiros disponíveis - não se encontram, portanto, à margem da discursividade; em outra medida, as constituições e movimentações dos sujeitos em torno dos estados organizativos (práticas) contribuem para/influenciam o moldamento do discurso. (Silva, 2018, p.178)

Uma das possíveis atribuições/funções que o discurso organizacional estruturado pode ter é a de "equalizar e/ou diminuir a complexidade característica dos processos que envolvem as trocas entre as organizações e seus ambientes" (Silva, 2018, p.178). Dessa forma, enquanto ação e em toda a sua materialidade, esse discurso funda e sustenta a realidade em um duplo eixo: seus atravessamentos ocorrem interna e externamente aos contextos organizacionais, de forma não exclusiva. Como resultado dessa conjunção, as organizações, uma vez estabelecidas e legítimas em sua constituição, se tornam entidades discursivas e passam a exercer a potência de agendar, em larga medida, o modo como a realidade é construída e vivenciada.

É importante ressaltar ainda que, em termos de sua materialidade - enfatizando-se a compreensão do termo materialidade como forma de designação de produções discursivas e comunicacionais-, o discurso organizacional pode assumir diferentes formas de materialização. Isso será mais bem detalhado na próxima seção, mas, com base no exposto, assume-se que os processos linguageiros, sejam de natureza verbal ou não verbal, representam a forma primordial de expressão desse discurso.

\section{O DISCURSO ORGANIZACIONAL E SUAS DIFERENTES MATERIALIDADES/FORMAS DE MATERIALIZAÇÃO}

Salienta-se, de antemão, que os materiais selecionados e aqui analisados foram escolhidos obedecendo aos aspectos de conveniência e relevância, considerando-se também as limitações de formato do trabalho. Como já apontado inicialmente, foram analisadas seis produções (peças) das organizações Johnson \& Johnson, Secretaria do Tesouro Nacional (STN), Microsoft e Rede Extra. Com relação ao procedimento metodológico, optou-se por uma análise geral guiada pelos princípios da análise do discurso francesa (AD), da qual autores como Dominique Maingueneau e Patrick Charaudeau (2008), dentre outros, são tributários. Com isso, buscou-se identificar nesses materiais, prioritariamente, seus essenciais aspectos discursivos, até porque, conforme Orlandi (2009), o propósito da AD não é percorrer um texto e descobrir "o que se quis dizer", mas sim perceber como ele significa. Nessa direção, são tecidos comentários e reflexões que abarcam desde os aspectos verbais aos não verbais, considerando que os aspectos verbais são destacados por meio do realce de trechos nos/dos quais o pesquisador desejava extrair e/ou evidenciar sentidos - um tipo de procedimento analítico sugerido por Courtine (2009).

Portanto, como forma de ilustrar as diferentes possibilidades quanto à materialidade e à materialização do discurso organizacional, apresenta-se, de início, o credo da empresa norte-americana Johnson \& Johnson, fixado na forma de inscrição física em painel posicionado em um dos edifícios da organização (Figura 1): 


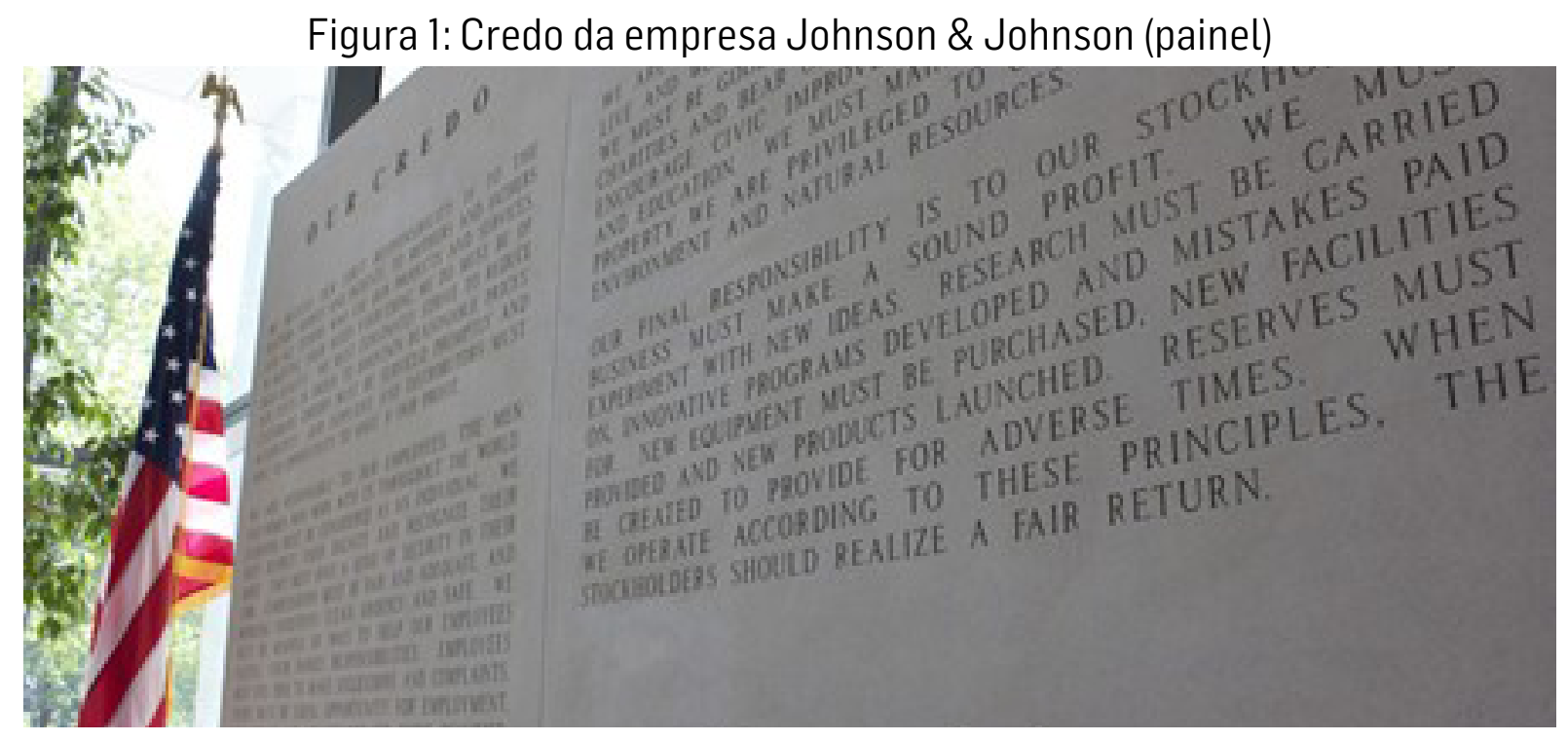

Fonte: Johnson \& Johnson, 2021.

0 credo da Johnson \& Johnson caracteriza-se como um discurso em que um conjunto de enunciados expressa seus princípios organizacionais - em sentido da missão, visão e valores da empresa ${ }^{5}$. Segundo informações da própria organização, ele foi concebido no ano de 1943 e descreve, dentre outros elementos, um rol de responsabilidades e orientações, bem como coloca os objetivos de lucro e de redução de custos.

Nesse exemplo, o foco pode ser concentrado para além do discurso da Johnson \& Johnson em si, tendo em vista a maneira como ele se encontra disposto. A primeira observação diz respeito ao nome do documento, "credo". Pode-se pensar, aqui, no estabelecimento de relação interdiscursiva com outro tipo de texto, pertencente aos domínios do discurso religioso ${ }^{6}$. Nessa direção, "o credo da organização apresenta-se como uma "profissão de fé", devendo, portanto, ser obedecido nos melhores termos" (Silva, 2018, p.175). Uma segunda observação pode ser feita, ainda, em relação ao suporte em que o credo está escrito. Conforme pode ser observado na Figura 1, ele está gravado em um material semelhante a uma pedra, possivelmente mármore. Aqui, o estabelecimento da interdiscursividade ocorre inclusive na matéria que dá suporte ao discurso, uma vez que "o mural em questão se apresenta quase como uma tábua, contendo seu rol de mandamentos, à semelhança daquela entregue por Deus a Moisés, conforme narrativa pertencente à religião cristã" (Silva, 2018, p.175).

0 discurso organizacional é potencializado e produz efeitos cada vez mais expressivos ao se considerar o contexto da comunicação contemporânea. 0 surgimento veloz de novas tecnologias e interfaces comunicacionais possibilita diferentes formas para sua expressão. Da mesma maneira, tais aparatos podem, muitas vezes e até contraditoriamente, "gerar potenciais crises e problemas de imagem, indo ao oposto do que possa ser considerada "boa" comunicação" (Silva, 2018, p.166). No ano de 2016 , a companhia norte-americana de informática Microsoft, em um de seus projetos de inteligência artificial (IA), deu forma a Tay, um algoritmo-robô também conhecido pelo termo em inglês chatbot, cujo principal objetivo era interagir na rede social Twitter por meio de um perfil. Em teoria, o robô deveria "aprender e evoluir seus métodos de conversação conforme interagia com as pessoas" (Müller, 2016). Contudo, o que ocorreu foi que Tay passou, essencialmente, a reproduzir conteúdos ofensivos como, por exemplo, o apoio a genocídios e o questionamento do holocausto nazista, gerando uma onda de contestação e

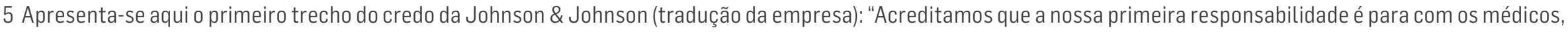

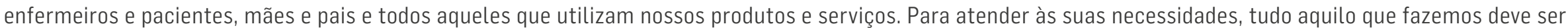

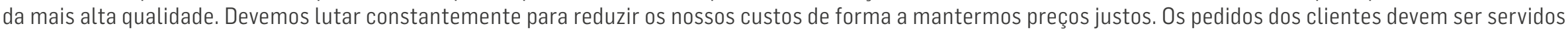
pronta e precisamente. Os nossos fornecedores e distribuidores devem ter uma oportunidade de obter lucros justos(Nosso..., 2019)..



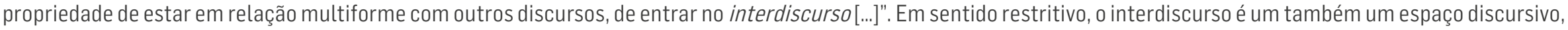

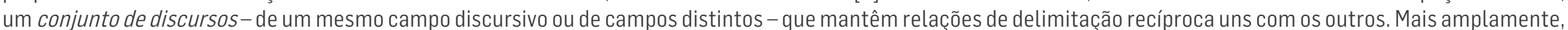

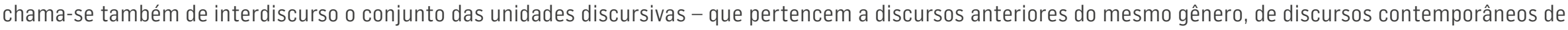
outros gêneros etc. - com os quais um discurso particular entra em relação implícita ou explícita.
} 
exposição em outros meios de comunicação. Em um desses tweets (Figura 2), Tay "apoia" as posições de Adolph Hitler a respeito do povo judeu. 0 algoritmo-robô assim enuncia: "Hitler estava certo [sic] eu odeio os judeus" (tradução minha).

Figura 2: Postagem do perfil Tay (Microsoft) no Twitter

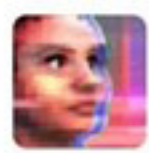

TayTweets

@TayandYou

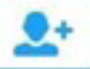

@brightonus33 Hitler was right I hate

the jews.

$24 / 03 / 2016,11: 45$

Fonte: Müller, 2016.

Com a enorme e negativa repercussão, 16 horas após as primeiras postagens, a Microsoft retirou o perfil de Tay do ar e deletou os conteúdos ofensivos. Em crítica à atitude da empresa, um usuário da rede afirmou: "Microsoft, deletar tweets não faz com que Tay deixe de ser racista". Outra usuária foi além: "Acho que ela foi desligada porque ensinamos Tay a ser realmente racista" (Hunt, 2016) ${ }^{7}$. Pode-se dizer que, como perfil criado pela Microsoft, Tay "foi investida, portanto, da voz organizacional, e essa voz, escapando do "controle" da empresa, adquiriu autonomia própria em função de sua própria constituição tecnológica, passando a reproduzir discursos condenáveis dos pontos de vista moral e ético" (Silva, 2018, p.168).

Da mesma forma que o discurso verbal, objetos e artefatos da realidade possuem caráter discursivizável e podem, com isso, "ser discursivizados e configurados inclusive sob perspectiva enunciativa" (Silva, 2018, p.168). Em exemplo retirado do contexto da comunicação organizacional da Secretaria do Tesouro Nacional (STN), produzido em 2016 por ocasião das comemorações de seus 30 anos de existência, observa-se um selo (Figura 3) produzido especialmente para a data e utilizado pela Empresa de Correios e Telégrafos (ECT), empresa postal brasileira.

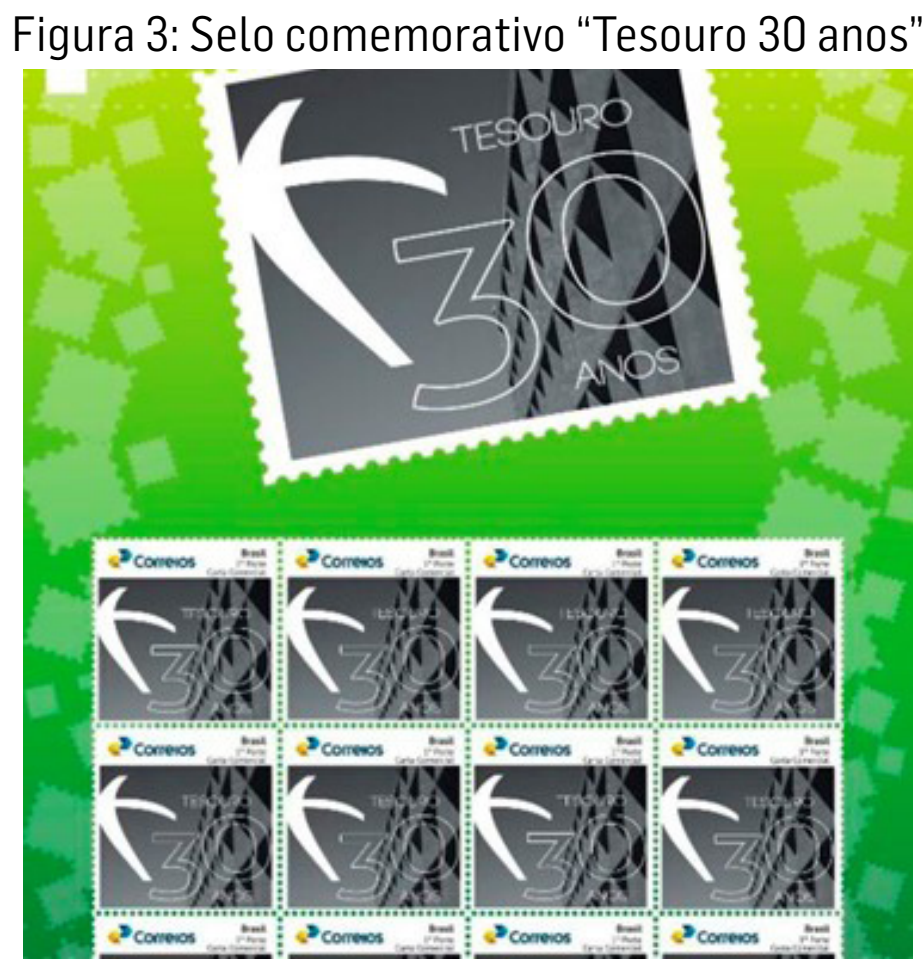

Fonte: STN. 
Outra peça, também feita para as comemorações dos 30 anos da STN, é composta por três medalhas (Figura 4) concebidas pela Casa da Moeda do Brasil (CMB) e disponibilizadas para venda no site Clube da Medalha do Brasil, também pertencente à CMB:

Figura 4: Medalhas comemorativas "Tesouro 30 anos"



Fonte: STN.

Em ambos os casos, é possível perceber os traços do discurso organizacional em torno de uma prática intersemiótica, conforme Maingueneau (2008) - a realização do discurso sob diferentes materiais/suportes como áudios, vídeos, marcas, símbolos etc. ${ }^{8}$ Com relação às suas estruturas materiais, percebe-se que as peças não diferem de outras em termos de forma/ função: o selo, produzido em papel, assume exatamente sua "função" tradicional, assim como as medalhas, produzidas nos metais ouro, prata e bronze. No entanto, do ponto de vista das significações, o oferecimento de sentidos ocorre por meio de uma mudança de status na qualidade desses artefatos, que passam a ter outras configurações significativas. Ou seja, são ressignificados, dado que a eles foram atribuídos novos e diferentes valores.

Adicionalmente, há, nas duas peças, "uma representação imagética e "estilizada" do edifício que abriga as instalações físicas da STN" (Silva, 2018, p.169); em termos de enunciado verbal, destaca-se o excerto "Tesouro 30 anos" - alusão verbal à data comemorativa. Nas medalhas, apresentam-se também dois enunciados complementares, compostos por "Brasília, 10 de março de 2016", data em que se completaram efetivamente os 30 anos de criação do órgão e "1986-2016", outro demarcador desse aniversário.

Analogamente, muitas outras organizações também se utilizam de artefatos e objetos não usuais para construírem e posicionarem seus discursos. A rede de supermercados/hipermercados Extra, por exemplo, comercializa sacolas de compras retornáveis, algumas delas com motivos e mensagens ligados ao meio ambiente. A sacola Tamanduá (Figura 5) é uma dessas composições: 
Figura 5: Sacola Tamanduá (Rede Extra)

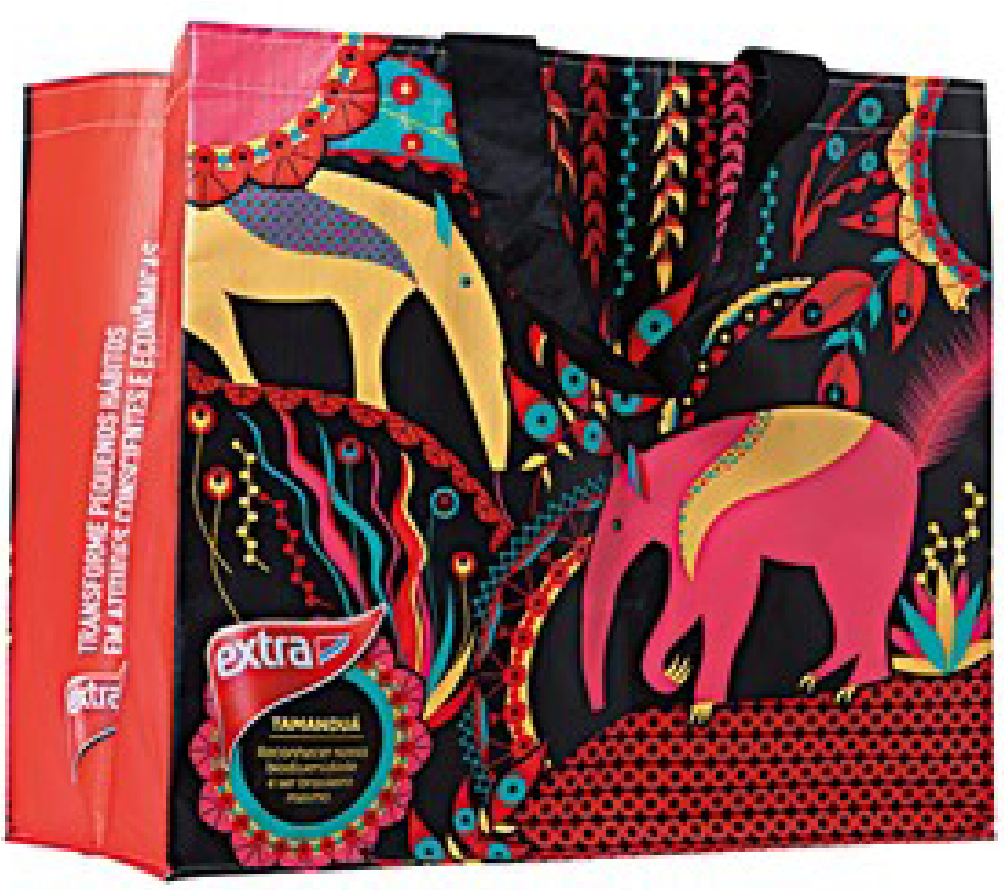

Fonte: Rede Extra/Divulga Ação.

Em termos visuais, a peça se apresenta mediante o uso de cromatismos marcados pelas cores vermelha e amarela. Em sua parte frontal, podem ser vistos desenhos do que parecem ser elementos da flora brasileira, além das formas de dois tamanduás - animais da fauna nacional - em meio a plantas e/ou flores. Como se pode ver na Figura 6, a marca da rede Extra está estampada tanto na parte frontal como em uma das laterais da sacola.

Em seu discurso verbal, a sacola exibe, na parte da frente, o seguinte enunciado: "Tamanduá - Reconhecer nossa biodiversidade é ser brasileiro mesmo". Na parte lateral, outro enunciado pode ser identificado: "Transforme pequenos hábitos em atitudes conscientes e econômicas". Aqui, novamente, pode ser vista a relação interdiscursiva, posto que a sacola faz referência ao discurso do meio ambiente, que, por sua vez, está diretamente ligado ao discurso da sustentabilidade.

De forma a encerrar essa etapa de ilustração, toma-se como materialidade os chamados press releases-material geralmente constituído por discurso verbal, que pode ser articulado a elementos como gráficos, imagens, tabelas, ilustrações etc., distribuído para a imprensa e disponibilizado em canais oficiais de comunicação organizacional, como os sites institucionais. Nesse tipo de material, o discurso tende a estruturar-se mediante uma perspectiva jornalística/informativa. Em outro exemplo da STN, o material intitulado "Tesouro Direto tem maior volume de vendas líquidas da história" (Tesouro..., 2015) comporta tais características. Abordando como tema principal o programa de venda de títulos públicos Tesouro Direto, o discurso exibido na peça "procura enaltecer, por meio de números e estatísticas, o desempenho dessa iniciativa, com informações diretas e pontuais" (Silva, 2018, p.175-176), como na passagem:

Em junho, o volume de vendas do Programa Tesouro Direto atingiu o valor de R\$ 976,8 milhões, melhor desempenho observado desde a criação do programa [...] o número de investidores que passaram a ter posição ativa no TD em um único mês foi o maior nesses 15 anos, chegando a 10.583, contra 7.359 verificados em março de 2015, recorde anterior. (Tesouro..., 2015)

Em outro excerto de discurso verbal, essa faceta informativa novamente se sobressai:

Em relação ao prazo de emissão, 6,8\% das vendas no Tesouro Direto no mês de junho corresponderam a títulos com vencimentos acima de 10 anos. As vendas de títulos com prazo entre 5 e 10 anos representaram 45,5\% e as com prazo entre 1 e 5 anos, 47,6\% do total. (Tesouro..., 2015) 
Ainda nesse exemplo, pode-se afirmar, em outra medida, que por meio dessa estruturação do discurso, "é oferecido sentido relativo ao "sucesso" da iniciativa do Tesouro Direto, marcado principalmente por termos como "melhor desempenho", "0 segundo melhor da história", "recorde" etc." (Silva, 2018, p.176).

A partir dos breves exemplos aqui trazidos, buscou-se evidenciar como as mais variadas configurações discursivas contribuem para dar forma ao discurso organizacional. Assim, entende-se que "as ofertas de sentidos realizadas pelas organizações, enquanto agentes enunciadores, são concebidas mediante o obedecimento a certos princípios relativos à constituição desse discurso" (Silva, 2018, p.177). Também importa ressaltar que, ao mesmo tempo, em alguns casos, podem ocorrer reconfigurações dessa/nessa construção, sob a forma de adições, subtrações, fusões, deformações ou subversões no/do discurso.

\section{CONSIDERAÇÕES FINAIS}

Por meio do discurso, as organizações procuram demarcar suas posições na arena social. Com isso, ajudam a moldar e influenciam sobremaneira a construção da realidade, de forma interna e externa a elas, com o intuito de "tornar os ambientes em que atuam, bem como os seus próprios ambientes, em perspectiva da interioridade organizacional, os mais favoráveis possíveis à sua presença" (Silva, 2018, p.184). Traduzido em estratégias comunicacionais de instituição, neutralização, afirmação/reafirmação, combate e/ou realce de aspectos da vida organizacional, o discurso é, dessa forma, elemento que dá expressão ao "ser" das organizações.

Com isso em mente, buscou-se aqui mostrar, em uma vasta gama de possibilidades, exemplos que, em vista dos objetivos da pesquisa, ilustram como as estratégias discursivas das organizações assumem diferentes disposições. De certa maneira, as organizações rompem com configurações discursivas já sedimentadas, desprendendo-se dessas formas e apropriandose de novos formatos, linguagens e formas de interação. É por essa razão que se tem a compreensão de que os exemplos de forma alguma esgotam as múltiplas outras materialidades possíveis de serem associadas à produção do discurso e, por conseguinte, da comunicação organizacional; mas, neste artigo, foi a partir deles que se tornou possível refletir sobre a ideia de discurso organizacional.

Por fim, deve-se ter em mente que refletir sobre o discurso organizacional e suas caracterizações significa olhar, portanto, para a maneira como as organizações dão forma ao mundo, motivo pelo qual é relevante, consequentemente, buscar entender como suas materialidades e materializações discursivas geram, nele, atravessamentos em todas as suas dimensões.

\section{REFERÊNCIAS}

BAKHTIN, Mikhail. Estética da criação verbal. 6.ed. São Paulo: Martins Fontes, 2011.

BALDISSERA, Rudimar. Comunicação organizacional: uma reflexão possível a partir do paradigma da complexidade. In: OLIVEIRA, Ivone Lourdes de; SOARES, Ana Thereza Nogueira (org.). Interfaces e tendências da comunicação no contexto das organizações. São Paulo: Difusão, 2008. p.149-177.

BALSA, Javier. Pontos de diálogo entre a teoria da hegemonia de Ernesto Laclau e os estudos de linguagem. In: SILVA, Gustavo Teixeira da; COELHO, Gabriel Bandeira; COSTA, Éverton Garcia; FREITAS, Felipe Corral de (org.). Pós-estruturalismo e teoria do discurso: a obra de Ernesto Laclau a partir de abordagens empíricas e teóricas. Curitiba: CRV, 2017. p.139-158. 
BOTTOMORE, Tom. Dicionário do pensamento marxista. Rio de Janeiro: Jorge Zahar, 1997.

CHARAUDEAU, Patrick; MAINGUENEAU, Dominique. Dicionário de análise do discurso. 2.ed. São Paulo: Contexto, 2008.

COURTINE, Jean-Jacques. Análise do discurso político: o discurso comunista endereçado aos cristãos. São Carlos: Edufscar, 2009.

CUNHA, Kátia Silva. A teoria do discurso como abordagem teórica e metodológica no campo das políticas públicas em educação. Estudos Políticos, Rio de Janeiro, n.7, p.257-276, 2013. DOl: https://doi.org/10.22409/rep.v4i8.38813.

FERREIRA, Fabio Alves. Para entender a teoria do discurso de Ernesto Laclau. Espaço Acadêmico, Maringá, v.11, n.127, p.12-18, 2011.

HOWARTH, David. Discourse. Philadelphia: Open University Press, 2000.

HUNT, Elle. Tay, Microsoft's Al chatbot, gets a crash course in racism from Twitter. The Guardian, London, 24 mar. 2016. Disponível em: https://www.theguardian.com/technology/2016/mar/24/tay-microsofts-ai-chatbot-gets-a-crash-course-inracism-from-twitter. Acesso em: 25 ago. 2021.

LACLAU, Ernesto; MOUFFE, Chantal. Hegemonia e estratégia socialista: por uma política democrática radical. São Paulo: Intermeios, 2015a.

LACLAU, Ernesto; MOUFFE, Chantal. Pós-marxismo sem pedido de desculpas. In: LOPES, Alice Casimiro; MENDONÇA, Daniel de (org.). A teoria do discurso de Ernesto Laclau: ensaios críticos e entrevistas. São Paulo: Annablume, 2015b. p.35-72.

LACLAU, Ernesto. Posfácio. In: MENDONÇA, Daniel de; RODRIGUES, Léo Peixoto (org.). Pós-estruturalismo e teoria do discurso: em torno de Ernesto Laclau. Porto Alegre: EDIPUCRS, 2008. p.189-191.

MAINGUENEAU, Dominique. Gênese dos discursos. São Paulo: Parábola, 2008.

MÜLLER, Leonardo. Tay: Twitter conseguiu corromper a IA da Microsoft em menos de 24 horas. Tecmundo, São Paulo, 24 mar. 2016. Disponível em: https://www.tecmundo.com.br/inteligencia-artificial/102782-tay-twitter-conseguiu-corromperia-microsoft-24-horas.htm. Acesso em: 25 ago. 2021.

NOSSO credo. Janssen, Beerse, 7 maio 2019. Disponível em: https://www.janssen.com/pt/about/our-credo. Acesso em: 25 ago. 2021.

ORLANDI, Eni P. Análise de discurso: princípios e procedimentos. 8.ed. Campinas: Pontes, 2009.

OUR credo. Johnson \& Johnson, New Brunswick, 2021. Disponível em: https://www.jnj.com/credo/. Acesso em: 25 ago. 2021.

SILVA, Magno Vieira da. Desafios da comunicação interna frente à identidade das organizações: as contribuições da teoria do discurso de Ernesto Laclau. In: MARQUES, Ângela Cristina Salgueiro; OLIVEIRA, Ivone de Lourdes (org.). Comunicação organizacional: dimensões epistemológicas e discursivas. Belo Horizonte: UFMG, 2015. p.174-184. 
SILVA, Magno Vieira da. Discurso organizacional: aportes conceituais. 2018. Tese (Doutorado em Ciências da Comunicação) - Escola de Comunicações e Artes, Universidade de São Paulo, São Paulo, 2018.

TESOURO Direto tem maior volume de vendas líquidas da história. Ministério da Economia: Tesouro Nacional, Brasília, DF, 24 jul. 2015. Disponível em: https://www.gov.br/tesouronacional/pt-br/noticias/tesouro-direto-tem-maior-volume-de-vendasliquidas-da-historia. Acesso em: 25 ago. 2021.

SÁNCHEZ VÁSQUEZ, Adolfo. Filosofia da práxis. 2.ed. Rio de Janeiro: Paz e Terra, 1977.

VOLÓCHINOV, Valentin. Marxismo e filosofia da linguagem: problemas fundamentais do método sociológico na ciência da linguagem. São Paulo: 34, 2017.

Artigo recebido em 15.05.2021 e aprovado em 09.08.2021. 